\section{Deep friezes}

\author{
Ann Sieveking
}

The Cave of Lascaux: The Final Photographic Record. By Mario Ruspoli. Thames \& Hudson, London/Harry N. Abrams, New York: 1987. Pp.208. £30, \$45.

Lascaux was closed to the public in April 1963 , having, in the 19 years since it was opened, become one of the world's most famous prehistoric monuments. The huge numbers of visitors (there were 122,000 in 1962) caused a rise in temperature and humidity in the cave that allowed algae to grow on the walls and threatened to ruin the paintings. The French Government bought the cave, closed it and facilitated the creation of a copy, 'Lascaux II', for the benefit of tourists. In addition, they decided, in 1981, to make a full cinematic record of the original and Mario Ruspoli was commissioned to do this.

The book is his personal contribution to this project: it is thoroughly researched and written for an interested general public. Although Ruspoli does not qualify his statements, and suppositions sometimes appear as facts, his appreciation of his subject, Palaeolithic art in general, Lascaux in particular and the way of life of its creators, is very well communicated. Certain aspects of the decoration, not apparent to an occasional visitor, were revealed by the conditions under which he worked. For example, his cameramen were restricted to using low lighting intermittently, and this sporadic and dim illumination exhibited the paintings as, perhaps, they were originally conceived. The friezes unfold before the viewer as he progresses, some figures recede, others emerge and some can be seen only from a succession of shifted positions. This is a situation that is familiar in Palaeolithic art; for example, the animals engraved on an antler shaft are curved around the convex surface so that they can be seen only in rotation - an aspect that still photographs and overall lighting cannot recreate.

\section{Mud matters}

\section{Jeffrey Wilson}

The Chemistry of Clays and Clay Minerals. Mineralogical Society Monograph No. 6. Edited by A.C.D. Newman. Longman: 1987. Pp.480. £48. To be published in the United States by Wiley, $\$ 110$.

ClAys and clay minerals occur in geological environments as diverse as soils, sediments and hydrothermally altered rocks and are utilized for a remarkable variety of purposes, particularly in the ceramic, paper, chemical and oil industries. These materials therefore occupy an important niche at the interface between earth sciences and industry and are often the focus of interdisciplinary efforts by a whole spectrum of scientists. A consequence of the wide interest in clays is that information on their chemistry in relation to their industrially useful properties is scattered throughout the literature and can sometimes be difficult to find.

This book represents a major effort to bring together and to present authoritative information on two disparate but closely related themes, namely the chemical constitution of the silicate clays with their associated iron, aluminium and manganese oxides and hydroxides and the properties of these materials that are most useful to man, particularly from an industrial point of view. These properties include colloidal stability, ion exchange behaviour, thermal reactions, interactions with water and organic substances and catalytic properties. Inevitably, with a multi-author book of this kind covering so many different aspects, there is a slight unevenness of treatment. For example, the approach adopted to describe the chemical constitution of clays is truly encyclopaedic and describes in detail not only those minerals that are clearly most important with regard to use, but also species that are at present probably of most direct concern to museum curators. In contrast, the cation exchange equilibrium of clays is dealt with in a mere ten pages of text and certainly some readers might have wished for more extensive coverage. Nevertheless, the overall balance between the chemical composition of clays on the one hand and the properties and behaviour of these materials on the other is about right, and the book will undoubtedly appeal to the international community of clay scientists and even to those with only a peripheral interest in clays.

The evolution of this book has not been without difficulty, as is frankly admitted by the editor in his preface. In fact, the project was initiated more than 15 years ago by the Clay Minerals Group of the Mineralogical Society and at one time, due to unforeseen circumstances, had almost foundered. Newman was appointed as editor and to supervise a rescue operation at a relatively late stage in the proceedings. It is a tribute to his patience and perseverance that the rescue was accomplished successfully and to his own scientific excellence that the final product is not just a bedraggled, out-of-date survivor, but a major contribution to clay science.

Jeffrey Wilson is head of the Department of Mineral Soils at the Macaulay Land Use Research Institute, Aberdeen AB9 $2 Q J, U K$.

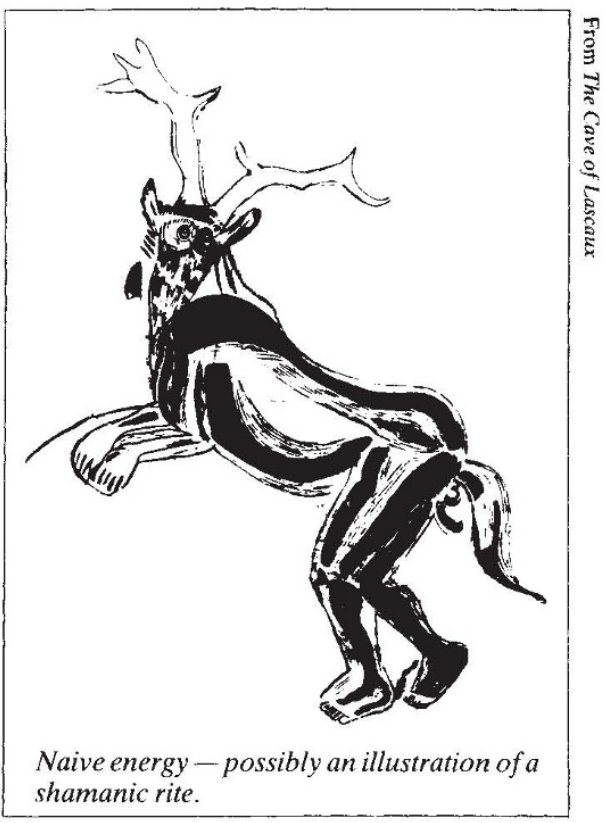

At Lascaux, the decorations exhibit an understanding of perspective in detail as in overall conception; for example, on many animals one leg is brought forward and the other placed in recession by erasing lines in the colour wash, and the topography of the cave is used as an inspiration for the layout of paintings and engravings. Here, as in all Palaeolithic caves, the decoration follows a strict formula in which certain animal species are associated, certain animals are depicted to suggest movement while others are static, and certain species are shown large or small. A marvellous variety of decoration is achieved within this format and the naivety of the figures gives them a particular energy. This is not a matter of anatomical depiction but is implicit in the size relation of the figures, the use of colour, the height of the friezes and the positions of the animals. Ruspoli's photographs communicate this alive and alert quality, although the plates are variable in the matter of colour. Lascaux is decorated in a warm spectrum and some of the photographs reproduced here are surprisingly cold.

Much of the technical information in the book is taken from Lascaux Inconnu (Arlette Leroi-Gourham et al., 1979. Editions du CNRS) or contributed by scholars such as Brigitte and Giles Delluc, who also contributed to the earlier publication. In Ruspoli's book it is summarized and in English, which is a benefit to anyone who has not read the French original. Communication is a skill that few research scholars possess and Ruspoli's understanding of popular needs was an asset in writing an accessible and informative book.

Ann Sieveking is an honorary research fellow at the London University Institute of Archaeology and author of The Cave Artists (Thames and Hudson, 1979). 